\title{
Numerical Simulation for Engine/Airframe Interaction Effects of the BWB300 on Aerodynamic Performances
}

\author{
Gang Yu $\mathbb{D},{ }^{1}$ Dong Li $\mathbb{D},{ }^{1}$ Yue Shu $\mathbb{D},{ }^{2}$ and Zeyu Zhang $\mathbb{D}^{1}$ \\ ${ }^{1}$ School of Aeronautics, Northwestern Polytechnical University, Xi'an 710072, China \\ ${ }^{2}$ AECC Sichuan Gas Turbine Research Establishment, Chengdu 610500, China
}

Correspondence should be addressed to Dong Li; ldgh@nwpu.edu.cn

Received 29 October 2018; Revised 25 January 2019; Accepted 17 February 2019; Published 15 May 2019

Academic Editor: Jose Carlos Páscoa

Copyright @ 2019 Gang Yu et al. This is an open access article distributed under the Creative Commons Attribution License, which permits unrestricted use, distribution, and reproduction in any medium, provided the original work is properly cited.

\begin{abstract}
The engine/airframe interaction effects of the BWB300 on aerodynamic performances were analyzed by using the numerical simulation method. The BWB300 is a 300-seat Blended Wing Body airplane designed by the Airplane Concept Design Institute of Northwestern Polytechnical University. The engine model used for simulation was simplified as a powered nacelle. The results indicated the following: at high speed, although the engine/airframe interaction effects on the aerodynamic forces were not significant, the airframe's upper surface flow was greatly changed; at low speed, the airframe's aerodynamic forces (of the airplane with/without the engine) were greatly different, especially at high attack angles, i.e., the effect of the engine suction caused the engine configuration aerodynamic forces of the airframe to be bigger than those without the engine; and the engine's installation resulting in the different development of flow separation at the airframe's upper surface caused greater obvious differences between the 2 configurations at high angles and low speed. Moreover, at low-speed high attack angles, the separated flow from the blended area caused serious distortion at the fan inlet of the engine.
\end{abstract}

\section{Introduction}

As air travel has grown over the years [1] so have concerns about both the exhaustion of fossil fuels and their contribution to climate change; therefore, there is now a need for more fuel-efficient aircraft for both economic and environmental reasons [2]. To achieve this goal, the Blended Wing Body (BWB), as an innovative concept [3], has received much attention for its high lift-to-drag ratio, low fuel cost, and low noise $[4,5]$. The BWB is an airplane with the wing blended to the body while still maintaining distinct wing and body structures [6]. It represents a potential revolution in subsonic transport efficiency for large airplanes [7].

The propulsion airframe integration design also plays a very important role in the good aerodynamic performance of the BWB $[8,9]$. For such integration design, the engine/airframe interaction effects on aerodynamic performances should first be known. The engine/airframe interaction effects are mainly determined by how the engine is installed.
The engine in conventional transport is often located beneath and ahead of the wing [10-12], but the engine installation on the BWB is often located over the wing and after the body $[13,14]$. This arrangement helps to offset the weight of the payload, furnishing, and other systems, thus ensuring a balanced airplane [15]. The engine mounting over the wing and after the body could be podded on a pylon or embedded in a boundary layer ingesting (BLI) arrangement [16-19]. In principle, the BLI arrangement can improve the propulsive efficiency by reducing ram drag. However, this assumes that an inlet can be designed that provides proper pressure recovery and uniform flow at the fan face of the engine [20]. Moreover, its pressure recovery is less than that of podded engines, which will lead to lower thrust [21]. The engine being podded on a pylon is traditional and involves little technical risk.

The Airplane Concept Design Institute of Northwestern Polytechnical University located in Xi'an, China, is now designing a 300-seat Blended Wing Body-the BWB300. The main design parameters of the BWB300 are as follows: 
(i) Cruising speed $0.85 \mathrm{Ma}$

(ii) Flight altitude $11.58 \mathrm{~km}$

(iii) Maximum range $13000 \mathrm{~km}$

(iv) Maximum takeoff weight $215000 \mathrm{~kg}$

Its propulsion system consists of 2 high-bypass ratio turbofan engines. We used the GEnx-1B64 engine. This engine is podded on a pylon to reduce the technical risk and enable the aircraft to rapidly enter the market. The BWB300 model is shown in Figure 1.

We used the numerical simulation method to analyze the engine/airframe interaction effects of the BWB300 on aerodynamic performance. The flow of the real engine is very complex, and therefore, we first had to simplify the engine model.

\section{Engine Model Simplification}

Since the aim of this paper was to analyze the engine/airframe interaction effects, we did not need to focus on the flow inside the engine. The interaction effects come from the shape of the nacelle and pylon and the inflow and outflow of the engine. Therefore, the engine model was simplified as shown in Figure 2; the outer part of the diagram shows the shape of the nacelle, and the performance of the inflow and outflow is determined by the fan inlet, fan exit, and core exit boundary conditions. This simplified model could be called a powered nacelle.

Hirose et al. [22, 23] simplified engines as illustrated above. They used the NAL-AERO-02-01 turbine-powered simulator (TPS) test model (as shown in Figure 3), which came from the National Aerospace Laboratory of Japan, to conduct numerical simulations. The numerical results matched well with the TPS test results. The control equations he used were Euler equations. However, in this paper, we used steady compressible 3-D Reynolds-Averaged NavierStokes (RANS) equations to simulate the engine installation effects. Therefore, the RANS equations were applied to reanalyze the model Hirose et al. used to see if our results would match those of the TPS test.

The detailed information of the RANS equations can be found in reference [24]. The RANS equations were discretized by the finite volume method, and the spatial discretization scheme was the second-order upwind Roe scheme. The turbulence model used was Menter's $k$-omega shear stress transport model [25] and the time stepping method was the implicit approximate factorization method. The wall functions were not used. The molecular viscosity was computed using Sutherland's law. The no-slip adiabatic wall boundary conditions were used on all solid surfaces (fan cowl, core cowl, spinner, and core spinner), and a characteristic-based boundary condition was used on the far field. The fan and core exit boundary conditions were the mass flow rate and stagnation temperature inflows, set with values for mass flux (i.e., mass flow ratio (MFR)) and total temperature (i.e., total temperature ratio). The fan inlet boundary condition was mass flow rate outflow, set with a mass flux balance with the fan and core flow.

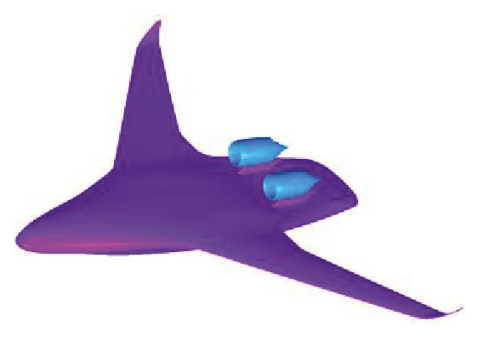

FIGURE 1: BWB300 model.

The grid used for computational fluid dynamics (CFD) calculations was a multiblock $\mathrm{O}-\mathrm{H}$ structure grid, and the number of volume grids was about 3 million. The grids were made with a $y+$ value of approximately 1 for the $0.80 \mathrm{Ma}$ condition. The far field boundary was located 10 body lengths from the configuration. Figure 4 shows the model's symmetry surface grid.

Two main criteria were used to monitor and determine the solution convergence. First, a drop in residual of at least three orders of magnitude was required. Second, the convergence of lift, drag, and moment coefficient was considered achieved when the maximum variation of the coefficient over 1000 iterations was less than $0.2 \%$ of the average coefficient value computed over the same range of iterations.

The computational states and parameters are shown in Table 1. In the table, $\mathrm{Ma}$ is the free stream Mach number. MFR is the mass flow ratio, BPR is the bypass ratio, $\alpha$ is the angle of attack, $T_{0 \mathrm{C}}$ is the total temperature at the core exit, $T_{0 \mathrm{~F}}$ is the total temperature at the fan exit, and $T_{0 \infty}$ is the total temperature of the free stream. The NAL-AERO-0201 fan cowl and core cowl pressure coefficient results of the CFD calculation and TPS test are compared in Figure 5. The results fit very well.

\section{Analysis of Engine/Airframe Interaction Effects on Aerodynamic Performance}

To analyze the engine/airframe interaction effects of the BWB300 on aerodynamic performance, the GEnx-1B64 engine was simplified as a powered nacelle. The aerodynamic performance of BWB300's airframe alone was also calculated for comparing with the performance of the whole model. To distinguish the 2 configurations used in this study, the airframe alone is called the clean configuration and the whole model is called the powered configuration.

Two typical states were evaluated: the high-speed state at the cruise Mach number and the low-speed state at the takeoff Mach number. The computational states are shown in Table 2. In the table, state1 is the high-speed state and its Mach number is 0.85 and state 2 is the low-speed state and its Mach number is 0.2. $\dot{m}_{\mathrm{fi}}$ is the mass flux at the engine's fan inlet, $\dot{m}_{\mathrm{fe}}$ is the mass flux at the engine's fan exit, $\dot{m}_{\mathrm{ce}}$ is the mass flux at the engine's core exit, and $T_{0 \mathrm{C}}$ and $T_{0 \mathrm{~F}}$ are as introduced in Table 1. These parameters were provided by the thermomechanical analysis of the engine to ensure that the engine's thrust was equal to the cruise condition requirement at state 1 and to the takeoff condition requirement at state2. 


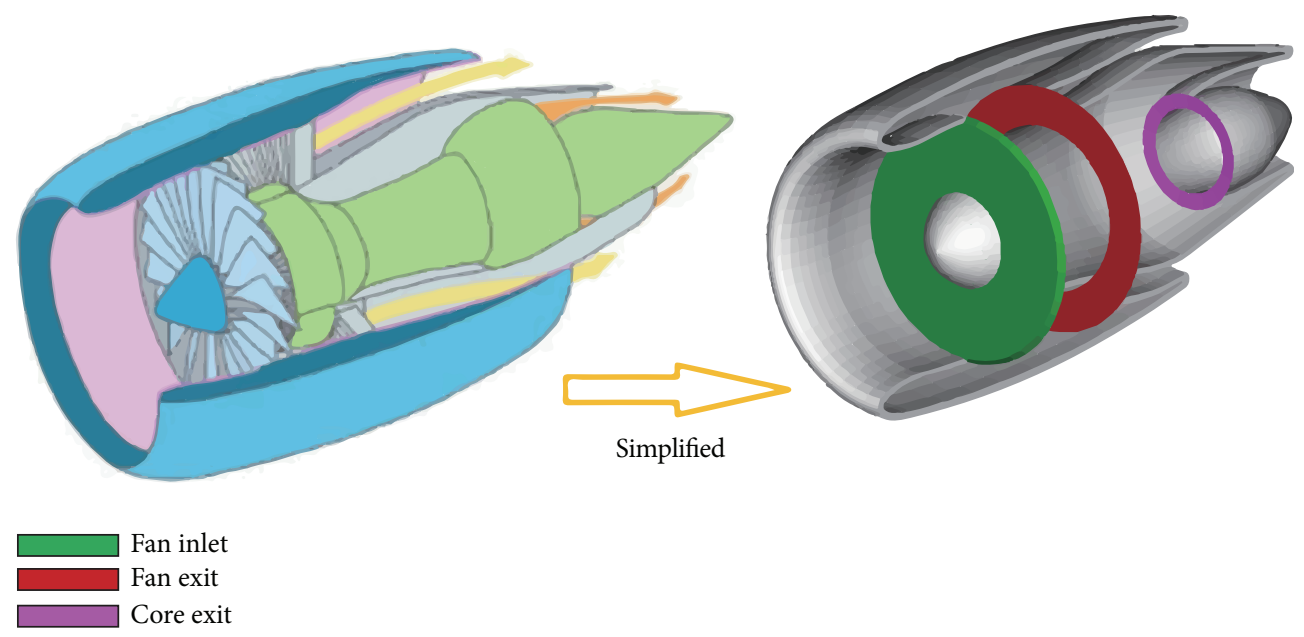

Figure 2: Engine model simplification.

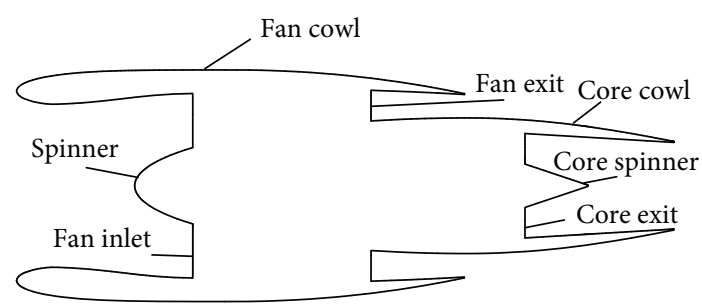

FIgURE 3: NAL-AERO-02-01 TPS test engine model.

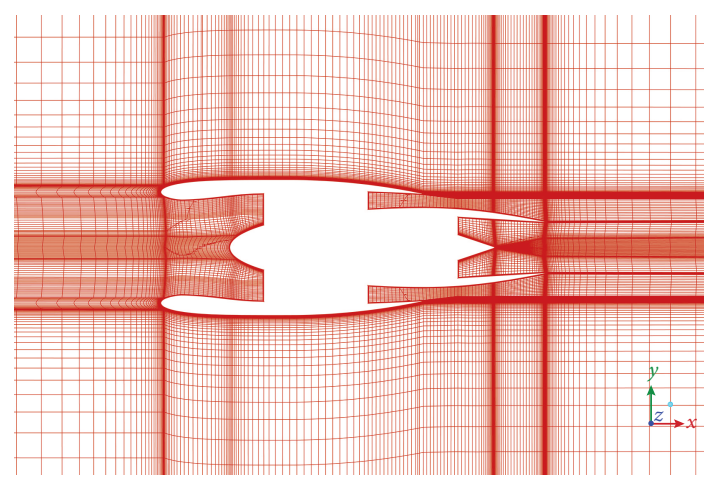

Figure 4: The symmetry surface grid of NAL-AERO-02-01.

TABLE 1: NAL-AERO-02-01 computation states.

\begin{tabular}{ccccccc}
\hline & $\mathrm{Ma}$ & $\mathrm{MFR}$ & $\mathrm{BPR}$ & $\alpha$ & $T_{0 \mathrm{C}} / T_{0 \infty}$ & $T_{0 \mathrm{~F}} / T_{0 \infty}$ \\
\hline 1 & 0.80102 & 0.52324 & 1.566 & $0^{\circ}$ & 0.60995 & 1.13299 \\
2 & 0.6024 & 0.49609 & 2.4917 & $0^{\circ}$ & 0.67204 & 1.06338 \\
\hline
\end{tabular}

The CFD calculation method used to calculate the clean/ powered configuration was the same as that introduced in the last section for the single engine calculation (but because at high angles $\left(\geq 11^{\circ}\right)$ and low speed the flow separation caused the aerodynamic forces to oscillate, the solutions at high angles and low speed are sought using unsteady ensemble averaged RANS); the steady solution convergence criteria were also the same. But the models used to calculate the aerodynamic performance were half models for reducing the CFD calculation cost. The unsteady solutions were solved by using the dual-time stepping method; the inner iteration tolerance was $0.2 \%$, and each cycle had 50 real-time steps. The simulation would be stopped when the periodicity was very stable; the results compared with the steady results were all time-averaged values. All solutions were computed at fullscale flight Reynolds numbers. For the clean configuration, no-slip adiabatic boundary conditions were used on all solid surfaces, a characteristic inflow and outflow boundary condition was used on the far field, and the symmetry plane was set as the symmetry boundary. For the powered configuration, except for these boundary conditions, the engine fan and core exits and fan inlet boundary need to be added. The fan and core exit boundary conditions were also the mass flow rate and stagnation temperature inflows, and the fan inlet boundary condition was also the mass flow rate outflow. To ensure that the results of the numerical solutions are reliable, the grid convergence study for the powered configuration was carried out.

3.1. Grid Convergence Study. The grids used for CFD calculations were multiblock O-H structure grids. Five levels of grids were generated with a far field extent of approximately 10 times the BWB300 body length. The total volume cell $N$ growth ratio between two adjacent grids is about 1.5 , and the corresponding node growth ratio along each direction between two adjacent grids is about $\sqrt[3]{1.5}$. G1 is the coarsest grid level, G2 is the second coarsest grid level, etc. The detail information on the five levels of grids is as shown in Table 3. (The grid $y+$ value equal to 1 for the BWB300 cruise condition is about $2 E-04 \mathrm{~m}$.) The closeup view of the engine grids for the powered configuration of G1, G3, and G5 is displayed representatively in Figure 6.

The aerodynamic force coefficients for the powered configurations of the five levels of grids at $1.5^{\circ}$ (high speed) and $5^{\circ}$ (low speed) are shown, respectively, in Figures 7 and 8. And the surface pressure distribution of the airframe for 


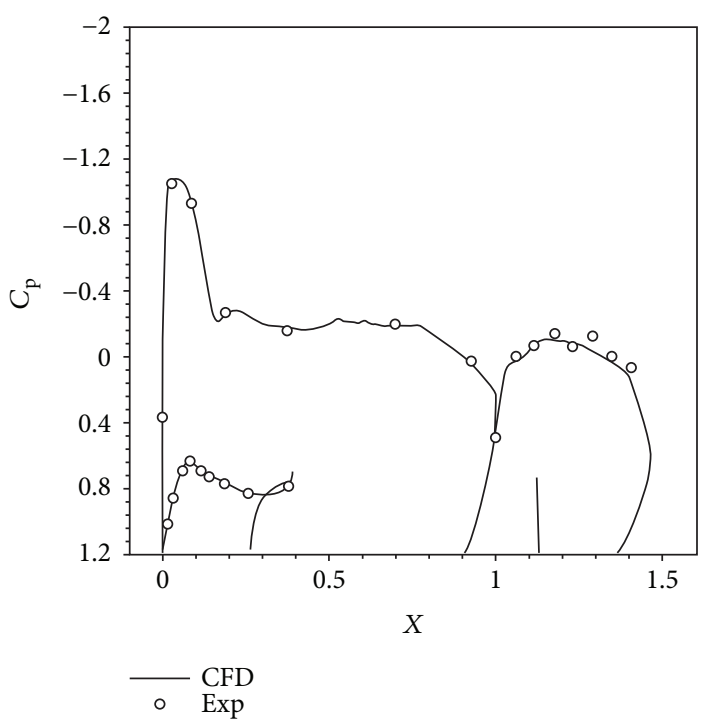

(a) State1

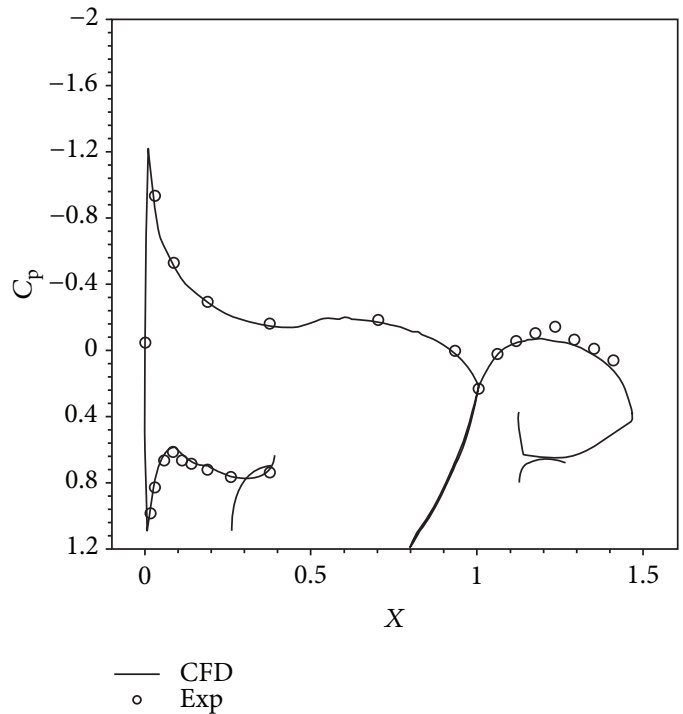

(b) State2

FIGURE 5: NAL-AERO-02-01 pressure coefficient results of the CFD calculation and TPS test.

TABLE 2: BWB300 computation states.

\begin{tabular}{ccccccc}
\hline & $\mathrm{Ma}$ & $\dot{m}_{\mathrm{fi}}(\mathrm{kg} / \mathrm{s})$ & $\dot{m}_{\mathrm{fe}}(\mathrm{kg} / \mathrm{s})$ & $T_{0 \mathrm{~F}}(\mathrm{~K})$ & $\dot{m}_{\mathrm{ce}}(\mathrm{kg} / \mathrm{s})$ & $T_{0 \mathrm{C}}(\mathrm{K})$ \\
\hline 1 & 0.85 & 418.5 & 377.8 & 281.9 & 40.7 & 675.9 \\
2 & 0.2 & 1093.7 & 987.8 & 291.9 & 106.0 & 742.1 \\
\hline
\end{tabular}

TABLE 3: Grid information.

\begin{tabular}{lcccc}
\hline & $\begin{array}{c}\text { First spacing } \\
\text { (in m) }\end{array}$ & $\begin{array}{c}\text { No. of } \\
\text { layers at } \\
\text { the trailing } \\
\text { edge }\end{array}$ & $\begin{array}{c}\text { No. of layers } \\
\text { in the viscous } \\
\text { padding }\end{array}$ & $\begin{array}{c}\text { Total volume cells } \\
\text { (in millions) }\end{array}$ \\
\hline G1 & $3.000 E-04$ & 7 & 17 & 4.94 \\
G2 & $2.600 E-04$ & 8 & 19 & 7.16 \\
G3 & $2.300 E-04$ & 10 & 22 & 11.21 \\
G4 & $2.000 E-04$ & 11 & 25 & 16.51 \\
G5 & $1.750 E-04$ & 13 & 29 & 25.81 \\
\hline
\end{tabular}

the powered configurations of the five levels of grids on the engine symmetry plane at $1.5^{\circ}$ (high speed) and $5^{\circ}$ (low speed) is shown in Figure 9. The $C_{\mathrm{L}}$ represents the lift coefficient, $C_{\mathrm{D}}$ represents the drag coefficient, $C_{\mathrm{M}}$ represents the pitch moment coefficient, alpha represents the angle of attack, and $C_{\mathrm{P}}$ represents the pressure coefficient. From these figures, it could be seen that with the grid refinement, the aerodynamic and pressure coefficients did not change much, especially from G4 to G5, where the results changed very little (all the differences of aerodynamic coefficients between G4 and G5 at high speed are less than 0.2\%; at low speed, they are a little larger (the $C_{\mathrm{L}}$ and $C_{\mathrm{M}}$ differences between G4 and G5 are less than $1 \%$, and the $C_{D}$ difference between G4 and G5 are about 1\%) but also acceptable). So the G4 grid could be considered reliable, and the following analysis was based on the calculation results of the G4 grid.

3.2. Engine Installation Effects on the Aerodynamic Performance of the Airframe. The engine/airframe interaction effects were divided into 2 parts: the engine installation effects on the aerodynamic performance of the airframe and the airframe effects on the inflow of the engine. These are discussed in the following subsections. The engine installation effects on the aerodynamic performance of the airframe are first analyzed from the aerodynamic forces of the clean and powered configurations.

3.2.1. Engine Installation Effects on the Aerodynamic Forces of the Airframe. The aerodynamic force coefficients of the clean configuration and powered configuration are compared in Figure 10. To compare the aerodynamic force effects clearly, the aerodynamic force coefficients were based ocnly on the airframe and the forces of the powered configuration's nacelle and pylon were not added in. The $K$ represents the lift-to-drag ratio.

From the lift curve in Figure 10, it can be seen that at high speed, the lift of the powered configuration was first smaller than that of the clean configuration; however, as the attack angle increased, the difference reduced. After the attack angle of $7^{\circ}$, the lift of the powered configuration started to become bigger than that of the clean configuration, and both configurations stalled at $9^{\circ}$. The drag of the 2 configurations was very close, and the drag of the powered configuration was first smaller than and then bigger than that of the clean configuration as the attack angle increased. Both configurations reached the maximum $K$ at the cruise attack angle of $1.5^{\circ}$, and the maximum $K$ value of powered configuration is bigger. This is nice for the 


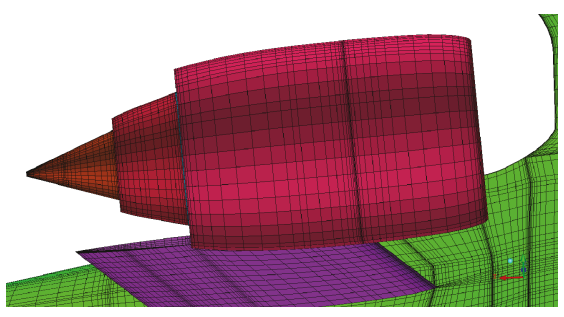

(a) G1

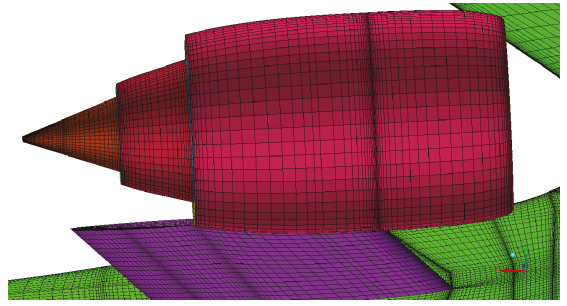

(b) G3

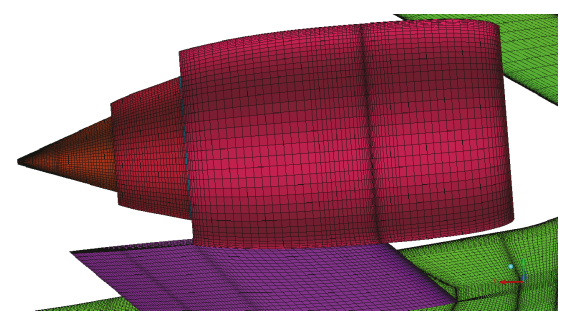

(c) G5

Figure 6: Closeup view of engine grids for the powered configuration of G1, G3, and G5.
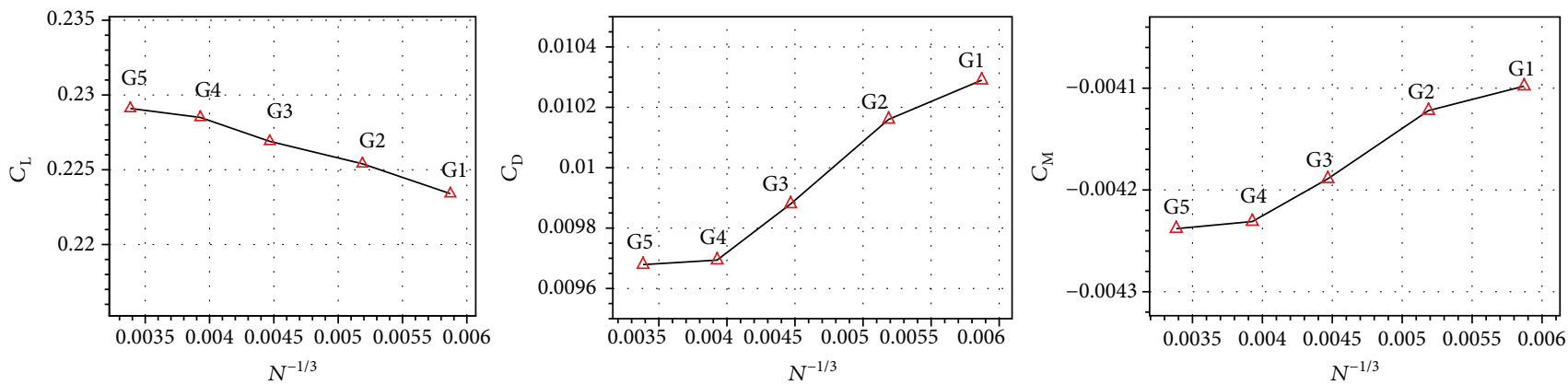

Figure 7: Aerodynamic forces for the powered configurations of the five levels of grids at $1.5^{\circ}$ (high speed).
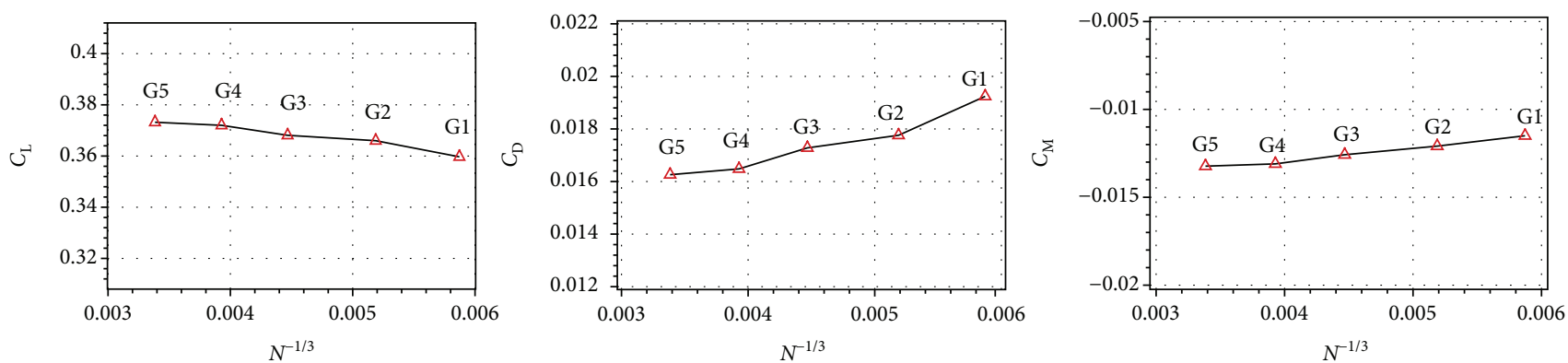

Figure 8: Aerodynamic forces for the powered configurations of the five levels of grids at $5^{\circ}$ (low speed).

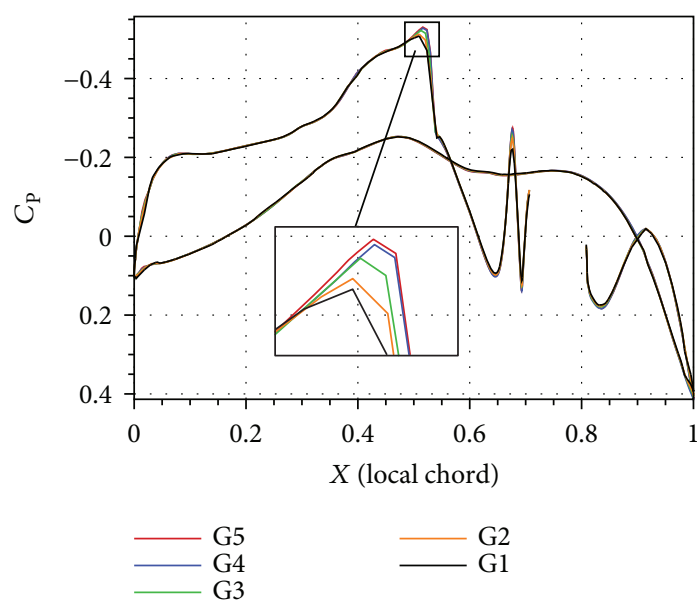

(a) $1.5^{\circ}$ high speed

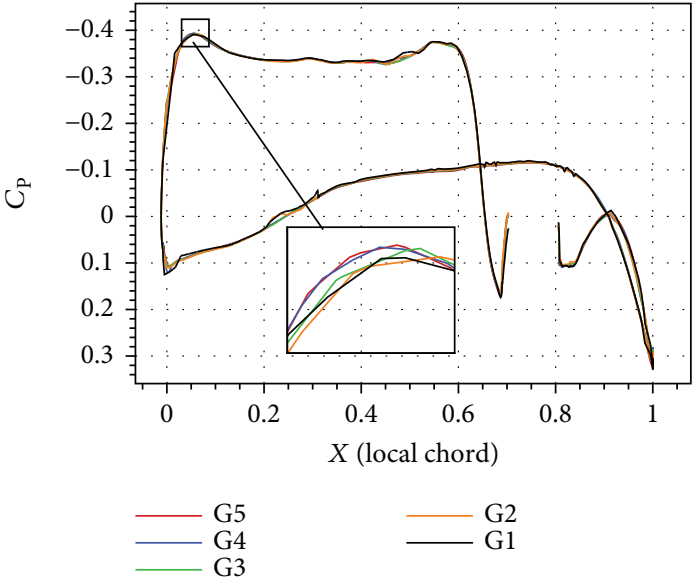

(b) $5^{\circ}$ low speed

FIGURE 9: Surface pressure distribution of the airframe for the powered configurations on the engine symmetry plane of the five levels of grids at $1.5^{\circ}$ (high speed) and $5^{\circ}$ (low speed). 

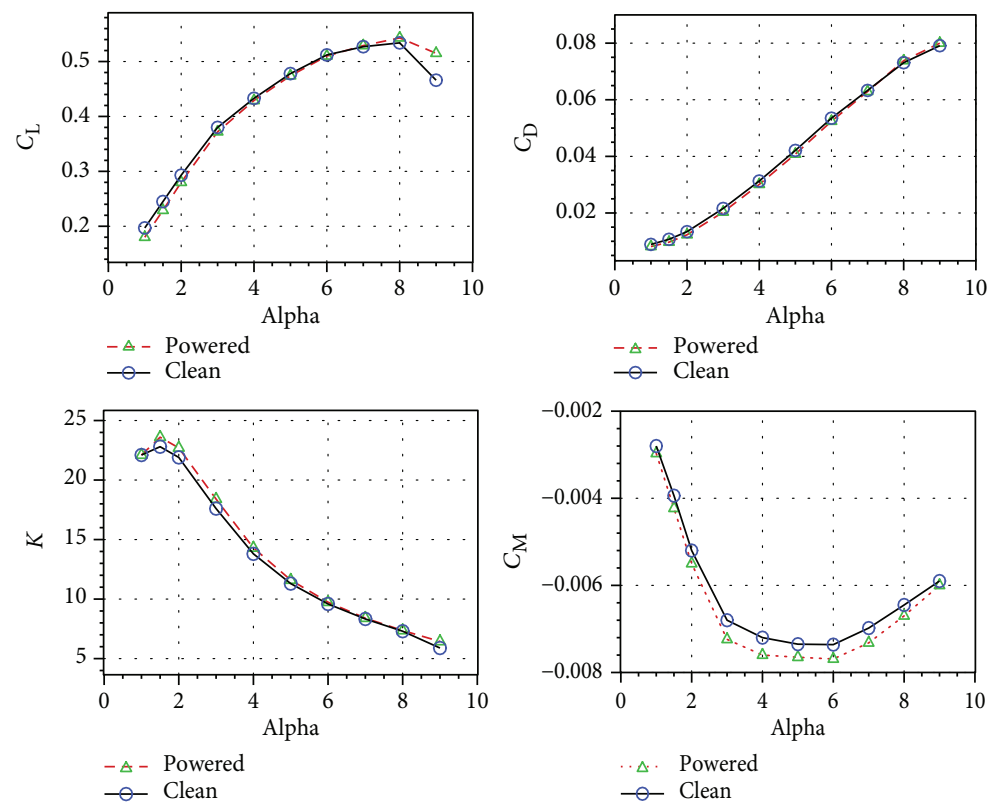

FIGURE 10: Comparison of aerodynamic forces for the clean and powered configurations at high speed.
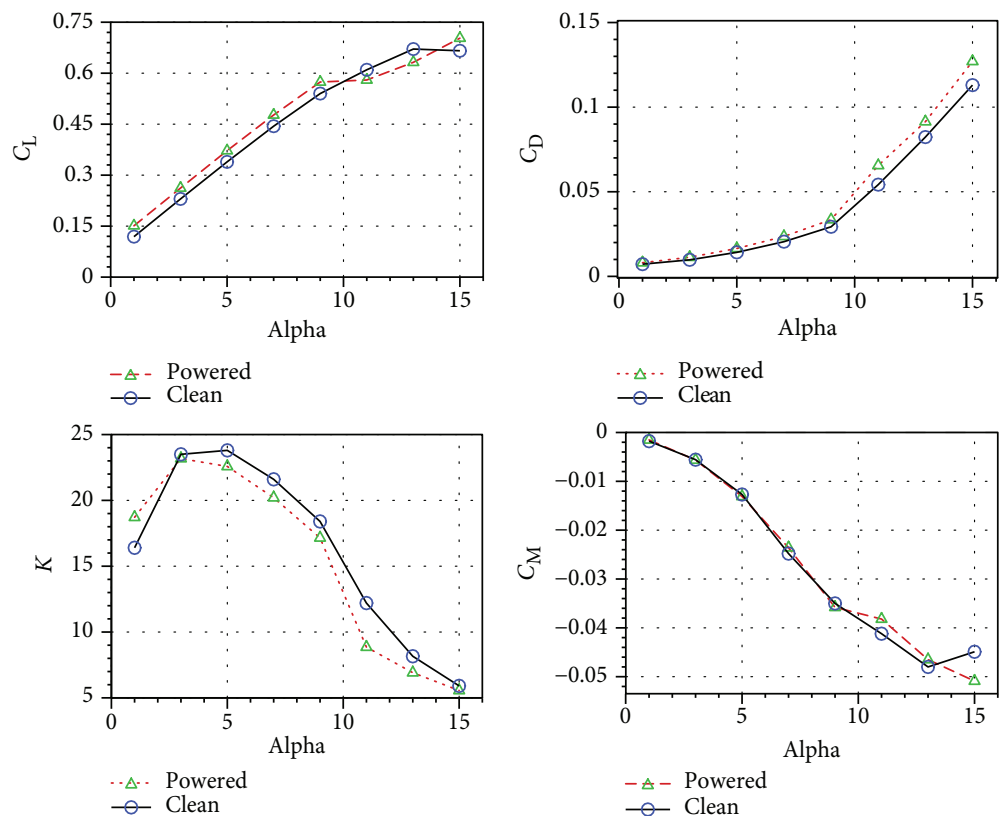

FIGURE 11: Comparison of aerodynamic forces for the clean and powered configurations at low speed.

airframe aerodynamic performance. However, the pitch moment trends were different. The pitch moment of the powered configuration was always smaller than that of the clean configuration, and the difference first increased and then decreased with increasing attack angle.

The aerodynamic force coefficient of the clean and powered configurations at low speed is compared in Figure 11. At low speed, the difference between aerodynamic forces of 2 configurations was bigger than that at high speed. Furthermore, the lift and drag of the powered configuration were nearly always bigger than those of the clean

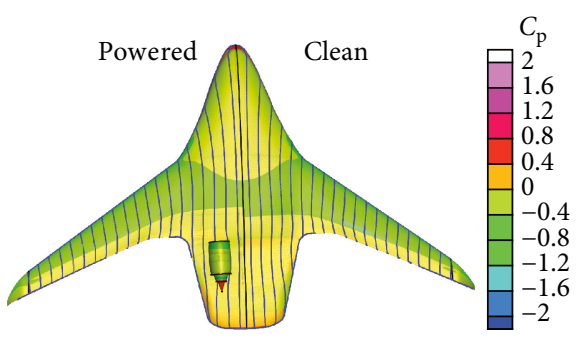

FIGURE 12: Upper surface pressure contour and streamlines of the clean and powered configurations at the cruise state. 


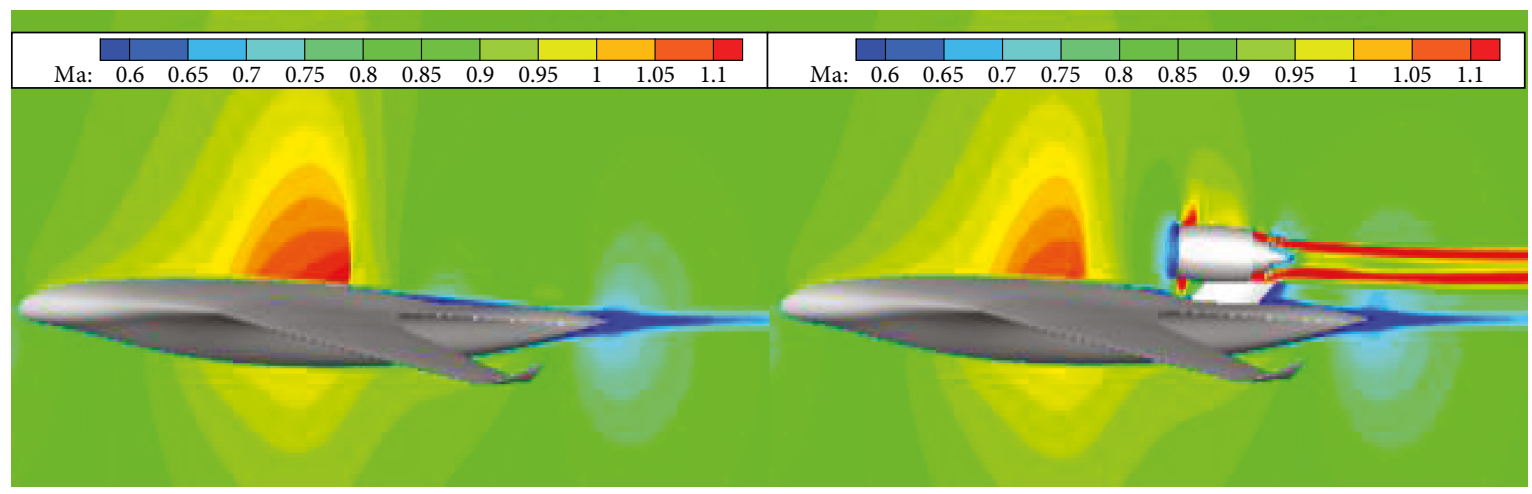

FIGURE 13: Whole model symmetric plane Mach number contour of the clean and powered configurations at the cruise state.

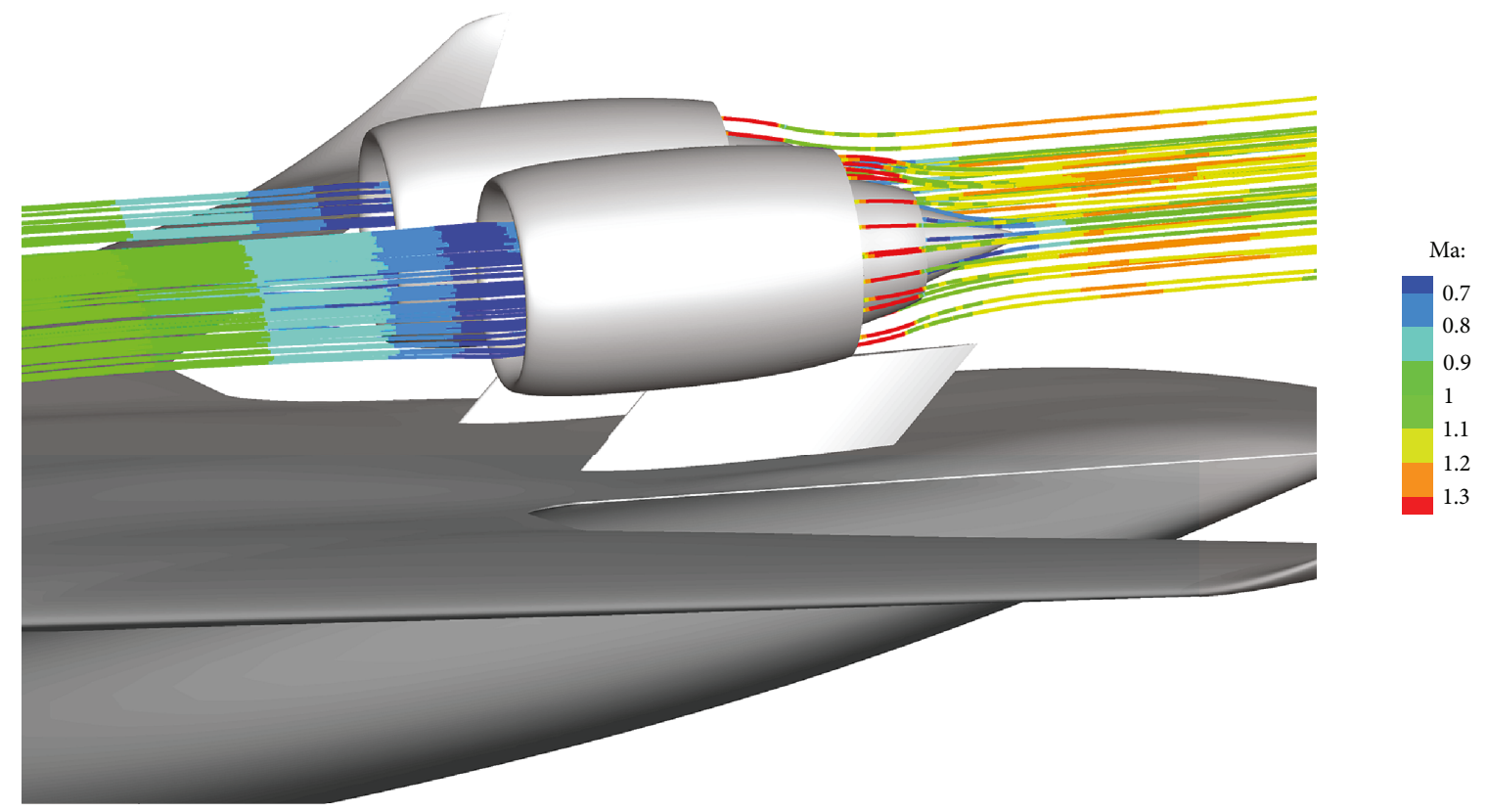

FIGURE 14: Inflow and outflow streamlines of the engine at the cruise state.
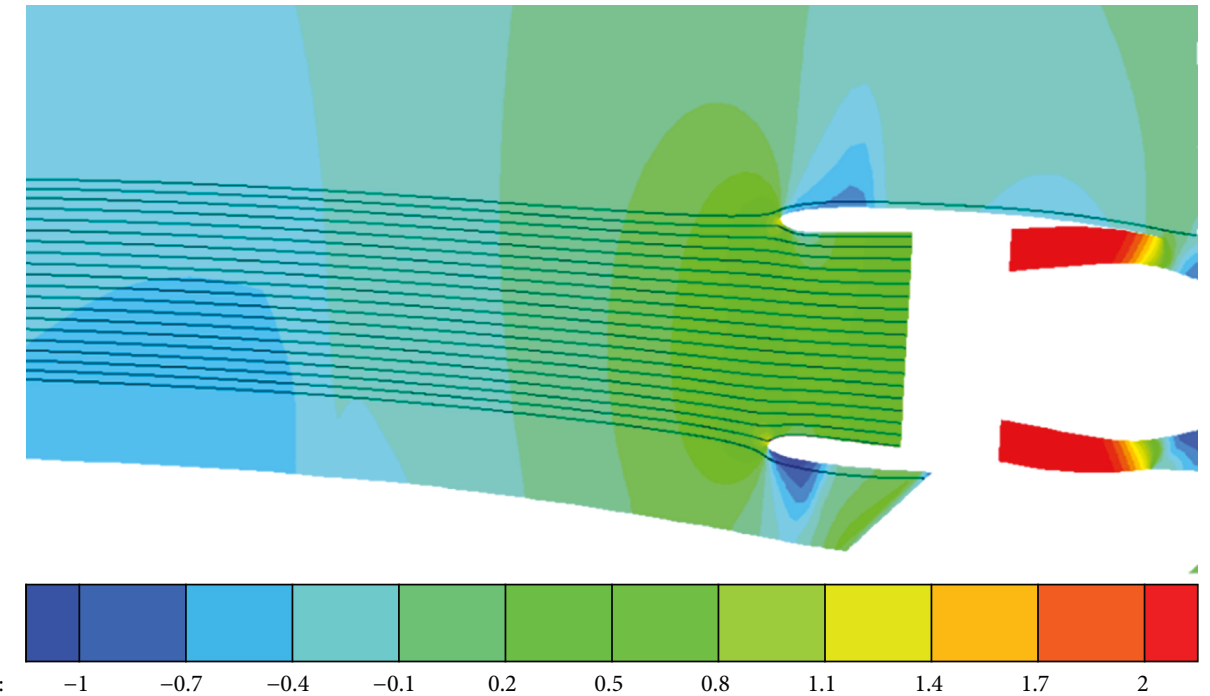

FIGURE 15: Inflow streamlines of the engine on its symmetry plane at the cruise state. 


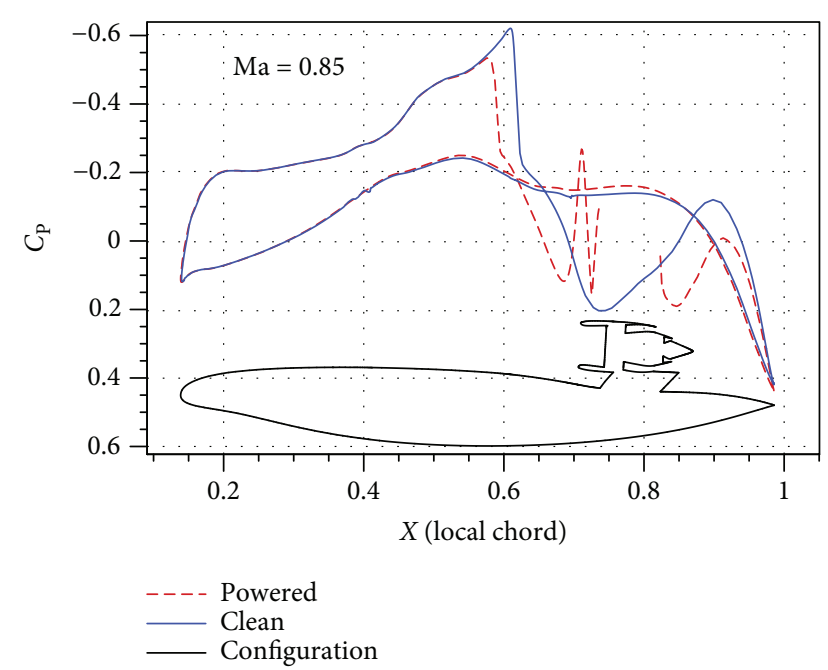

FIgURE 16: Surface pressure distribution of the airframe on the engine symmetry plane at the cruise state.

configuration. At the lift curve's linear segment, the difference between the lifts of the two configurations was basically constant. However, the power configuration's lift curve then flattened at $11^{\circ}$, and then it increased again while the clean configuration's lift reduced at $15^{\circ}$. The difference between the drag of the 2 configurations always increased with increasing attack angle. Lastly, the pitch moment of the 2 configurations was nearly all the same except at the high attack angle.

The differences between aerodynamic forces resulted from the differences between the surface flows of the 2 configurations. From the above analysis, it was seen that at high speed, the differences in aerodynamic forces were small, but at low speed, the differences were bigger especially at high attack angles above $11^{\circ}$. The reason for these differences is that the airframe's upper surface flow changed due to the engine installation effects.

3.2.2. Engine Installation Effects at High Speed on Aerodynamic Performance of the Airframe. The cruise state at high speed was analyzed in detail to see the surface flow difference. The upper surface flow pressure contour and the streamlines at the cruise state of the 2 configurations are shown in Figure 12. It can be seen that because of the engine installation, the position of shock waves on the upper surface moved forward and the shock wave strength changed. Figure 13 shows the Mach number contour on the symmetry plane of the whole model (2 engine configurations). The engine installation not only changed the shock wave strength but there were also weak shock waves on the engine upper and lower surfaces. Moreover, the flow velocity was slower near the engine inlet and behind the pylon. The fan outlet flow velocity was very high and existed for a long distance.

The inflow and outflow streamlines of the engine are shown in Figure 14. It can be seen that the velocity of the flow at the front of the engine was decreased and the outflow of the fan exit first accelerated and then decreased. The streamlines were not very close to the airframe's upper surface and did not directly affect the surface flow.

Figure 15 shows the inflow streamlines of the engine on its symmetry plane. It can be seen that the airflow was expanded a little at the engine inlet. Furthermore, the shock wave on the engine's lower surface was very close to the airframe's upper surface and may have affected the airframe's upper surface.

Figure 16 shows the pressure distribution of the airframe on the engine's symmetry plane. It can be clearly seen that because of the engine's installation near the engine, the upper surface pressure distribution changed greatly. The shock wave position on the upper surface moved forward to the $60 \%$ local chord, and its strength was reduced. After the shock wave, the surface flow velocity was first reduced and then accelerated to the front of the engine inlet. Then, the surface flow velocity was reduced again by an extra weak shock wave. Behind the engine, although the engine outflow velocity was very high, because of the existence of the engine, the flow of the powered configuration was slower than that of the clean configuration.

The pressure distributions at different spanwise positions are shown in Figure 17. It can be seen that the difference between the shock wave positions at the flow directions of the 2 configurations reached a maximum at the blended area. Moreover, at the sections near the wingtip, this difference became very small.

From the above analysis, we found that although at the cruise state the engine installation effects on the aerodynamic forces were small, the retardative effects caused by the existence of the engine mostly making the airframe's upper surface flow were greatly changed, while the engine inflow and outflow effects were not obviously. To be more specific, at the cruise state, the engine installation effects on the surface flow were as follows:

(1) The engine installation reduced the airframe's upper surface shock wave, moved the shock wave's position forward, and produced an extra shock wave

(2) Along the flow direction, the areas affected by the engine installation were concentrated near the shock wave; outside this area, there was nearly no effect

(3) Along the spanwise direction, the engine installation's effect on the center body and blending area was significant. As the distance to the engine increased, the effect on the wing decreased. Near the wingtip, there was nearly no effect

(4) Because the engine was installed over the upper surface, it had little effect on the lower surface

3.2.3. Engine Installation Effects at Low Speed on Aerodynamic Performance of the Airframe. At low speed, the $9^{\circ}$ attack angle state was analyzed in detail to see the difference in surface flow. The upper surface's flow pressure contour and the streamlines at the cruise state of 

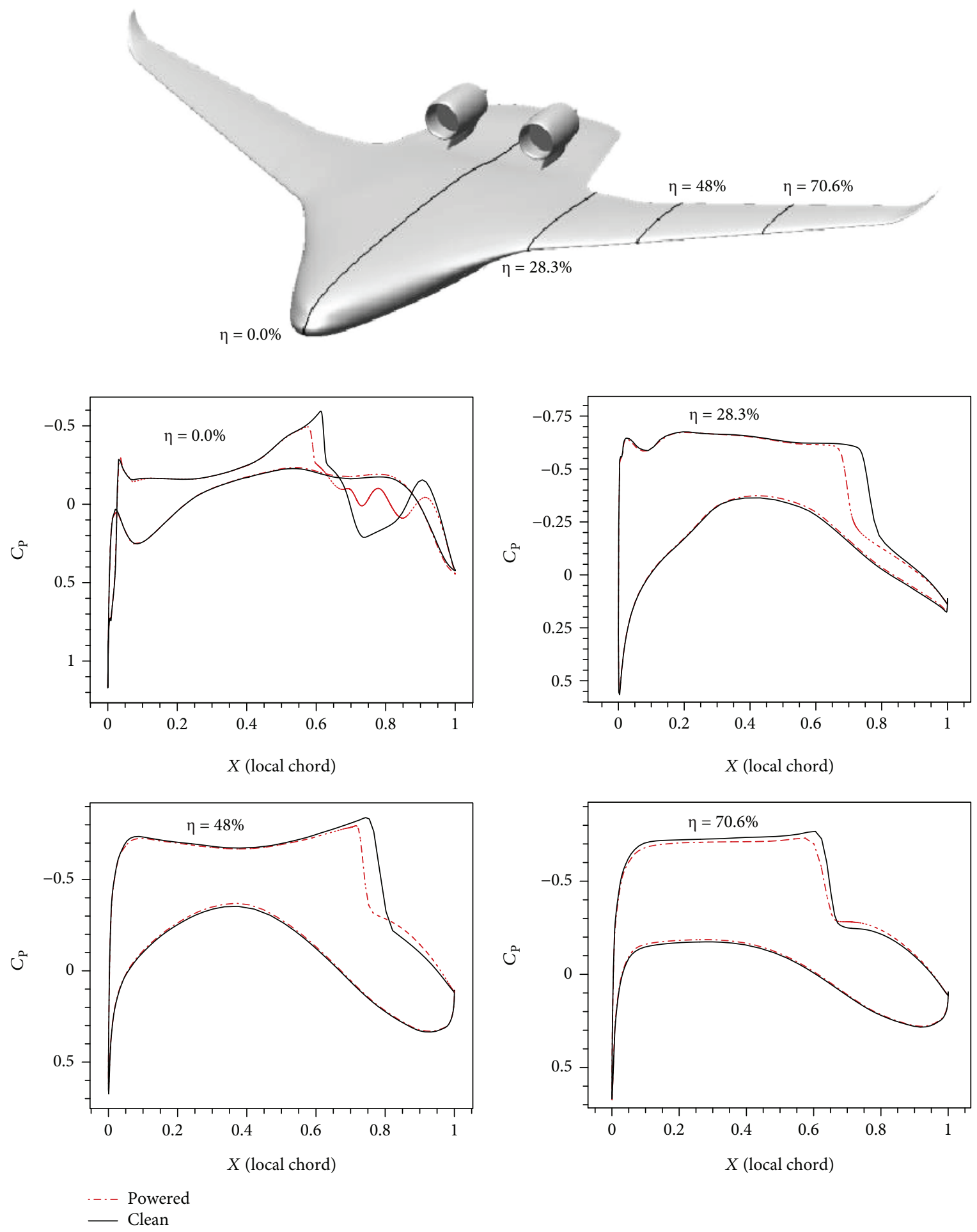

Figure 17: Pressure distribution of different spanwise sections at the cruise state.

the 2 configurations are shown in Figure 18. It can be seen that because of the existence of the engine, the surface flow streamlines in front of and behind the engine converged. Figure 19 shows the Mach number contour on the symmetry plane of the airplane. It can be seen from the figure that the engine inlet seemed to suck in all the upper surface's flow at its front. Figure 20 shows the inflow and outflow streamlines of the engine, and Figure 21 shows the inflow streamlines of the engine on its symmetry plane. It can be clearly seen from the figures that the inflow was 


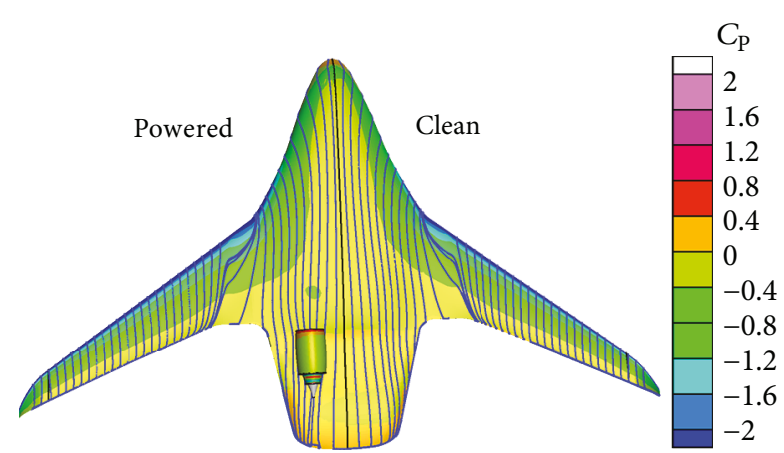

FIGURE 18: Upper surface pressure contour and streamlines of the clean and powered configurations at $9^{\circ}$ (low speed).

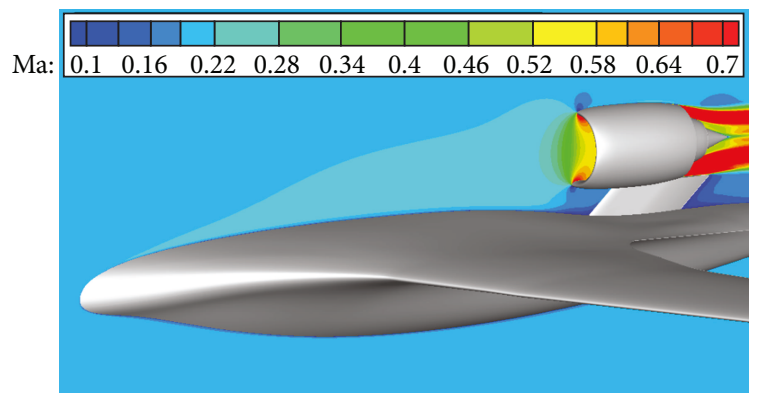

Figure 19: Airplane symmetric plane Mach number contour of powered configurations at $9^{\circ}$ (low speed).

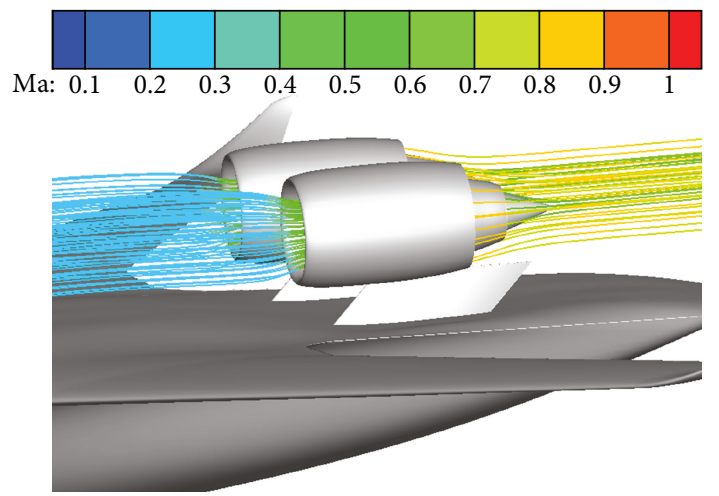

FIGURE 20: Inflow and outflow streamlines of the engine at $9^{\circ}$ (low speed).

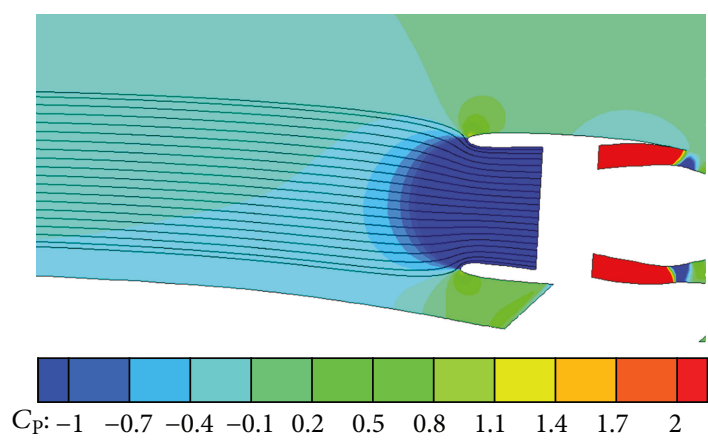

FIGURE 21: Inflow streamlines of the engine on its symmetry plane at $9^{\circ}$ (low speed).

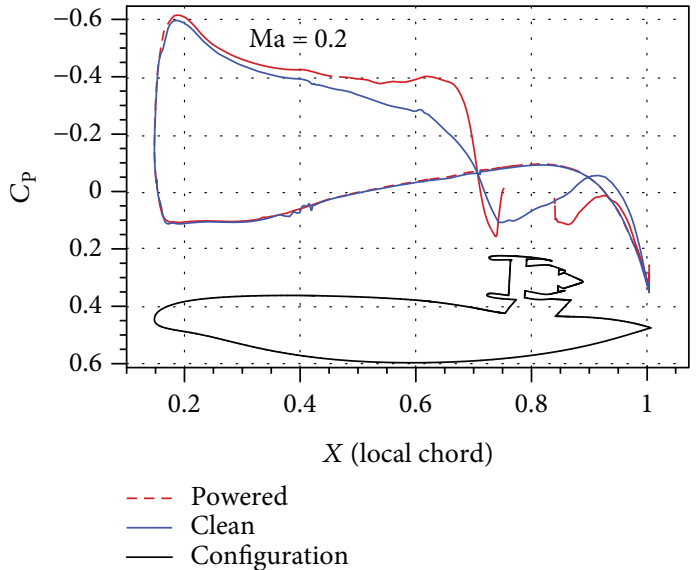

FIgURE 22: Upper surface pressure distribution airframe on the engine's symmetrical plane at $9^{\circ}$ (low speed).

accelerated and converged at the engine inlet. Though the inflow streamlines are not directly from the airframe upper surface, they are closer than at high speed. Therefore, the engine inflow effects at low speed should be bigger than those at high speed.

Figure 22 shows the pressure distribution of the airframe on the engine's symmetry plane. It can be clearly seen that, because of the engine's installation, the upper surface pressure distribution was nearly all changed. The surface flow at the front of the engine was accelerated compared to that in the clean configuration because of the engine sucking in air. This is the main reason why the lift and drag forces of the powered configuration were bigger than those of the clean configuration. Additionally, the surface flow behind the engine was also slower than that in the clean configuration.

From Section 3.2.1, it is clear that there was a greater obvious difference between the aerodynamic force characteristics of the powered and clean configurations at a low speed and attack angle above $11^{\circ}$. The reasons for this phenomenon are analyzed below.

This great difference occurs because of the different flow separation at high angles, which also causes the flow's total pressure to be reduced. To see the flow separation changing in 3-dimensional space clearly, the pressure ratio (PR) distribution was used to analyze the flow separation. The PR is defined as the ratio of the total pressure of the local place to the total pressure of the free stream [26]. Figure 23 shows the PR distribution of the clean and powered configurations at low speed.

It can be found from Figure 23 that, because of the engine's installation, at high attack angles, the differences in surface flow separation between the clean and powered configurations are as follows:

(1) The separation area of the clean configuration was first smaller than that of the powered configuration, but it enlarges faster as the attack angle increased and became larger than that of the powered configuration at $15^{\circ}$. And the separation area of the clean configuration reduced obviously behind the 
Alpha $=9$

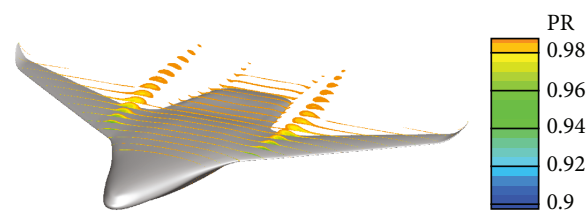

Alpha $=11$
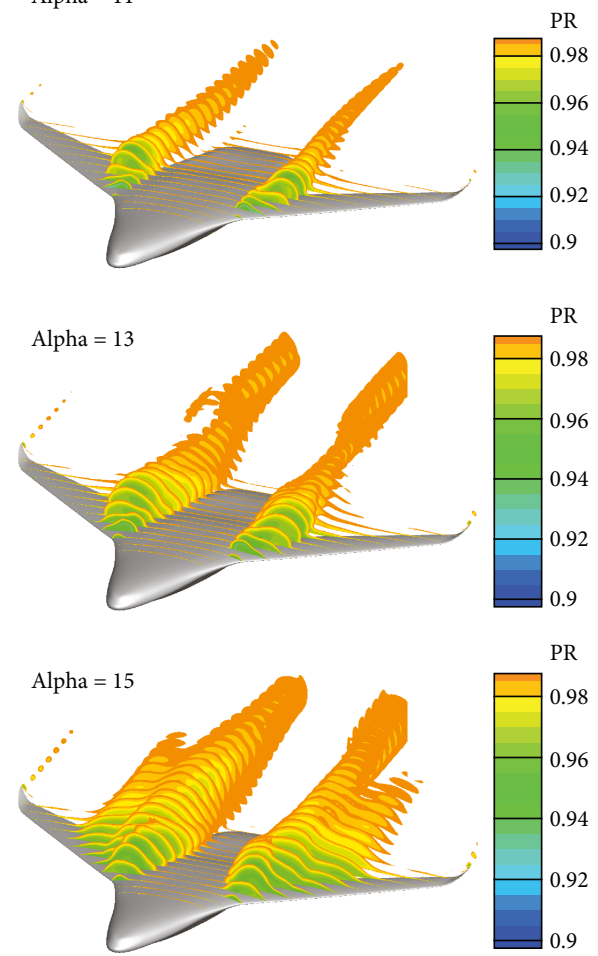

Alpha $=9$

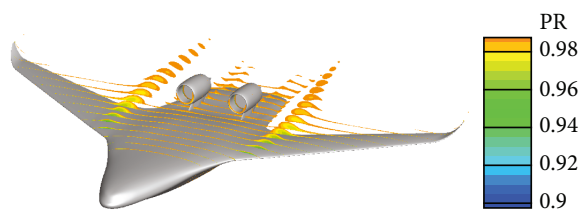

Alpha $=11$
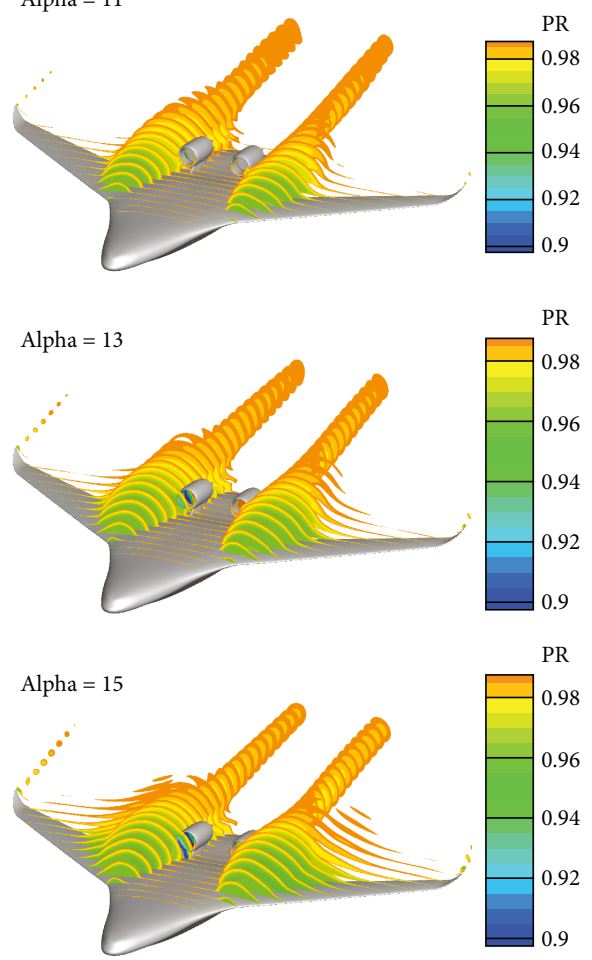

FIgURE 23: Upper surface PR distribution of the clean and powered configurations at high angles and low speed.

Alpha $=1$

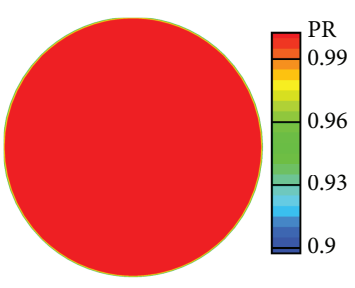

Alpha $=3$

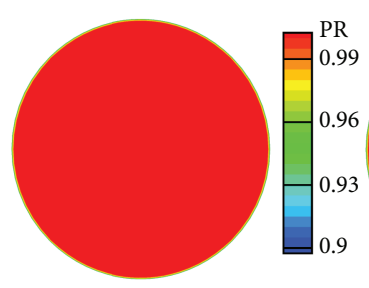

Alpha $=5$

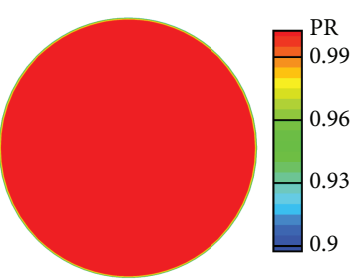

Alpha $=7$

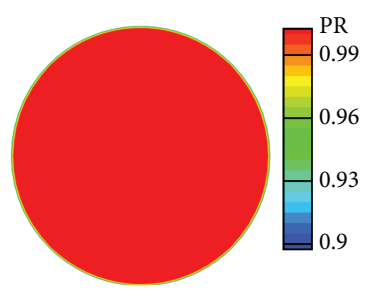

FIgURE 24: The inlet distortion of the BWB300 at different attack angles (high speed).

airframe. However, the separation area of the powered configuration was very steady behind the airframe

(2) The separation of both configurations first occurred at the blended place. For the clean configuration, because of the cross flow caused by the large leading sweep angle of the airframe, the center of the separation vortex gradually moved to the wingtip. However, for the powered configuration, the center became more steady because of the engine's inflow effects

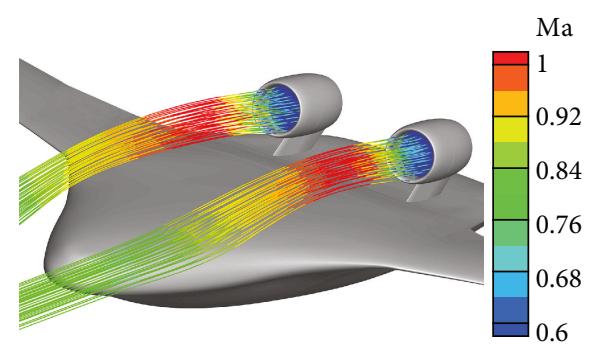

FIGURE 25: The inflow streamlines of the BWB300 at the cruise state. 


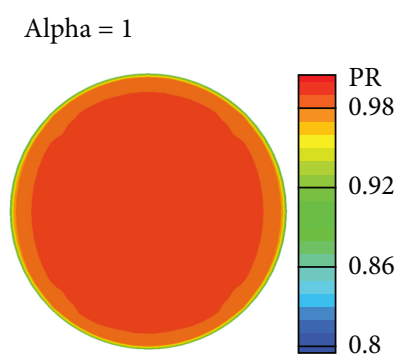

Alpha $=3$

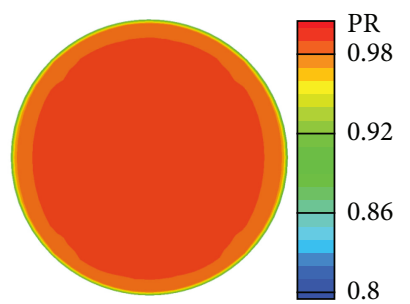

Alpha $=9$
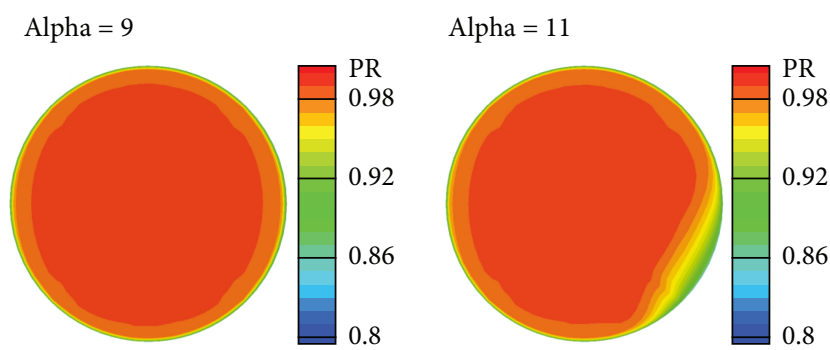

Alpha $=17$

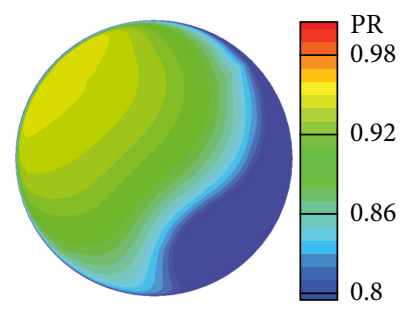

Alpha $=5$

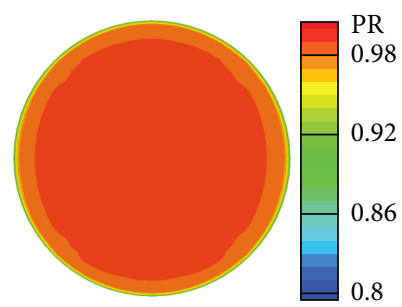

Alpha $=13$

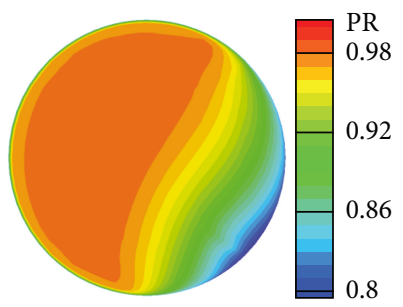

Alpha $=19$

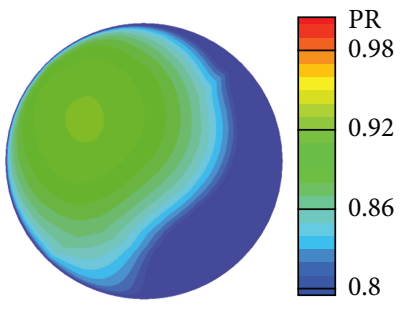

Alpha $=7$

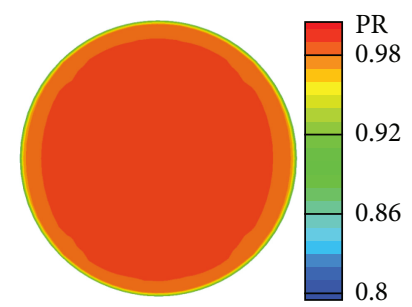

Alpha $=15$

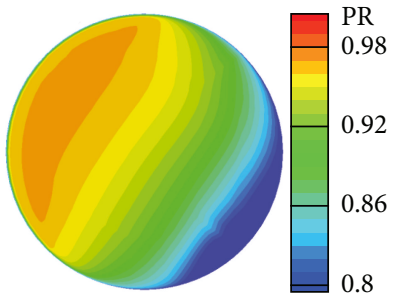

FIgURE 26: The inlet distortion of the BWB300 at different attack angles (low speed).

(3) When the separation vortex left the airframe of the clean configuration, it deviated upward because of the lower flow's effect. Conversely, for the powered configuration, because of the engine's outflow effect, the separation vortex kept the original direction well (which was the same as the outflow's direction).

(4) In the clean configuration, as the attack angle increased, there were more than 1 separation vortices occurring and then 2 merged vortices left from the airframe's upper surface. However, for the powered configuration, there was only 1 main vortex

Therefore, because of these flow separation differences caused by the engine's installation, the aerodynamic forces of the powered and clean configurations had greater obvious differences at high angles and low speed.

3.3. Airframe Effects on the Inflow of the Engine. Because the engine was located over and after the BWB300's upper surface, its inflow was easily influenced by the flow distortion caused by the airframe. This would lead to a reduction in engine efficiency and perhaps the engine being unable to work properly. Therefore, analysis of airframe effects on the engine's inflow was very necessary. The inlet distortion at high and low speeds was analyzed to see the inflow's qualities, and the inlet distortion was evaluated by using the PR distribution. The total pressure recovery coefficient $\sigma$ was defined as $\sigma=P_{0 \mathrm{CA}} / P_{0 \infty}$. The $P_{0 \mathrm{CA}}$ is the average total pressure at the fan inlet, and $P_{0 \infty}$ is the total pressure of the freedom flow.

3.3.1. Inlet Distortion at High Speed. The inlet distortion at different attack angles at high speed before stalling is shown in Figure 24. It can be seen that at high speed before stalling, the pressure distribution at the fan inlet was very uniform and there was no inlet distortion. Moreover, the $\sigma$ of these states were all above 0.99 , indicating that the inlet efficiencies of these states were all very high and satisfied the design requirements. The inlet streamlines of all these states were similar those at the cruise state, which are shown in Figure 25. Although the streamlines were influenced by the airframe to deflect near the blended area, the streamlines did not experience distortion and flowed into the fan inlet uniformly. Thus, at high speed before stalling, the engine inflow was not affected by the airframe and the engine had good efficiency.

3.3.2. Inlet Distortion at Low Speed. The inlet distortion of different attack angles at low speed is shown in Figure 26. It can be seen that at small angles $\left(\leq 7^{\circ}\right)$, there was also no inlet distortion. Furthermore, the $\sigma$ of these states were all above 0.989 , indicating that the inlet efficiencies of these states were also very good. Therefore, at small angles and low speed, the 



Figure 27: The inlet distortion of the engine alone at different attack angles (low speed).

airframe did not affect the engine inflow and the engine also had good efficiency.

However, as the angle increased from $11^{\circ}$, there was obvious distortion occurring at the engine's fan inlet. The lowpressure area first occurred at the fan inlet's bottom right, and then with the increasing angle, it gradually enlarged at both sides.

To compare with these results, the inlet distortions of the engine alone at these high attack angles (and at low speed) were also calculated. The calculating condition was the same as for the whole airplane. These results are shown in Figure 27. The $\sigma$ at these states are compared in Figure 28.

It can be seen from Figure 28 that before the flow separation, the value of $\sigma$ was almost the same at the inlet of the BWB300 and its engine alone. However, as the angle increased, the engine-alone value of $\sigma$ was nearly unchanged while that of the BWB300 decreased. Therefore, with an increasing angle, the effect of the airframe on the engine became more and more serious.

The effect of the airframe on the engine can also be seen from the inlet flow streamlines. The inflow streamlines of the BWB300 at $13^{\circ}$ are shown in Figure 29. At a high angle, the separated flow caused by the blended area was sucked into the engine's inlet, thus causing a low-pressure area. Then, the flow separation area enlarged as the angle increased, enlarging the low-pressure area at the fan inlet. This seriously affects the engine's inflow characteristics.

\section{Conclusion}

Engine/airframe interaction effects of the BWB300 on aerodynamic performances were analyzed in this paper using CFD. The results were as follows:

(1) At high speed, the engine installation effects on the aerodynamic forces of the airframe were small; at low speed, the effects were bigger. At low speed, the

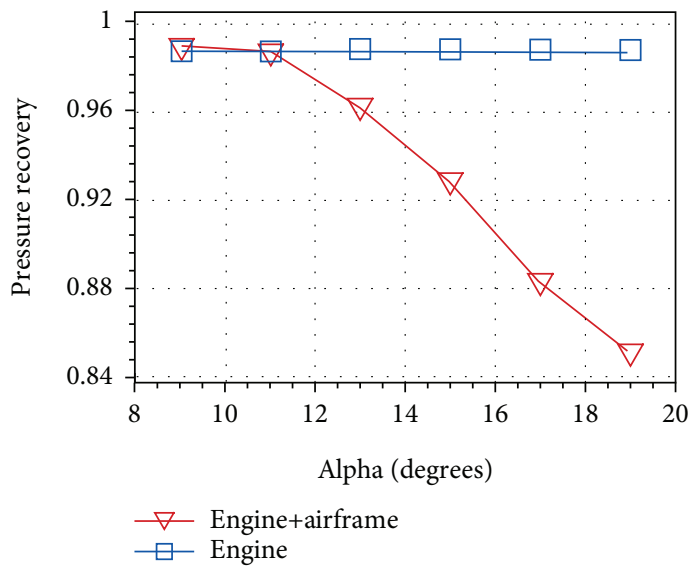

FIGURE 28: The inlet distortion of the engine alone at different attack angles (low speed).

lift and drag forces of the powered configuration were nearly all larger than those of the clean configuration and the differences of the 2 configurations were obviously greater at high angles

(2) Although at high speed the engine installation effects on the aerodynamic forces of the airframe were small, the upper surface flow was greatly changed. It is mostly because of the retardative effects caused by the existence of the engine. The engine inflow and outflow effects are not obviously

(3) At low speed, the engine sucking in air caused the lift and drag forces of the powered configuration to be bigger than those of the clean configuration. And the engine's installation resulting in the different development of flow separation at the airframe's upper surface caused greater obvious differences between the 2 configurations at high angles and low speed 


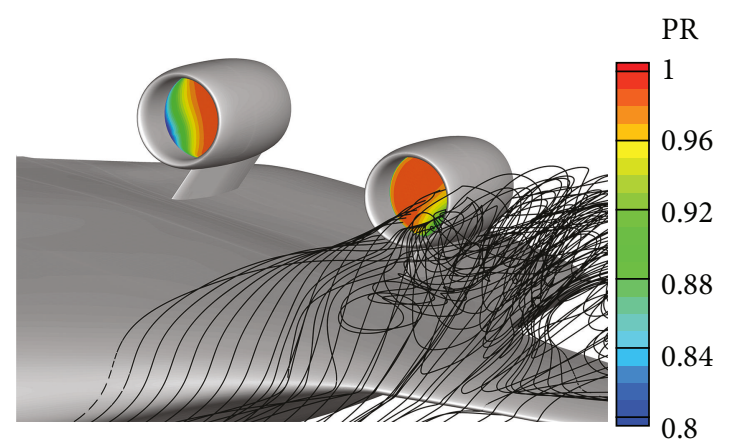

FIGURE 29: The inflow streamlines of the BWB300 at $13^{\circ}$ (low speed).

(4) At high speed before stalling, the engine inflow was not affected by the airframe and the engine had good efficiency. This was also seen at small angles and low speed

(5) At large angles and low speed, the separate flow caused by the blended area was sucked into the engine's inlet, causing a low-pressure area at the fan inlet. As the angle increased, the flow separation area enlarged, thus enlarging the low-pressure area at the fan inlet. This seriously affected the engine's inlet flow characteristics

\section{Data Availability}

All data included in this study are available upon request by contact with the corresponding author.

\section{Conflicts of Interest}

The authors declare that they have no conflicts of interest.

\section{References}

[1] M. D. Guynn, J. E. Freh, and E. D. Olson, "Evaluation of a hydrogen fuel cell powered blended-wing-body aircraft concept for reduced noise and emissions," Tech. Rep. NASA/ TM-2004-212989, NASA Langley Research Center, 2004.

[2] T. A. Reist and D. W. Zingg, "Aerodynamic design of blended wing-body and lifting-fuselage aircraft," in 34th AIAA Applied Aerodynamics Conference, p. 3874, Washington, DC, USA, 2015.

[3] M. Brenner, J. Trepanier, C. Tribes, and E. Petro, "Conceptual design framework for blended wing body aircraft," in 12th AIAA Aviation Technology, Integration, and Operations (ATIO) Conference and 14th AIAA/ISSMO Multidisciplinary Analysis and Optimization Conference, p. 5649, Indianapolis, IN, USA, 2013.

[4] P. Dehpanah and A. Nejat, "The aerodynamic design evaluation of a blended-wing-body configuration," Aerospace Science and Technology, vol. 43, no. 3, pp. 96-110, 2015.

[5] R. Martínez-Val, C. Cuerno, E. Pérez, and H. H. Ghigliazza, "Potential effects of blended wing bodies on the air transportation system," Journal of Aircraft, vol. 47, no. 5, pp. 1599-1604, 2010.
[6] P. R. Shea, J. D. Flamm, K. Long, K. D. James, D. Tompkins, and M. D. Beyar, "Turbine powered simulator calibration and testing for hybrid wing body powered airframe integration (invited)," in 54th AIAA Aerospace Sciences Meeting, p. 11, San Diego, CA, USA, 2016, AIAA SciTech Forum.

[7] R. Liebeck, M. Page, and B. Rawdon, "Blended-wing-body subsonic commercial transport," in 36th AIAA Aerospace Sciences Meeting and Exhibit, p. 438, Reno, NV, USA, 1998.

[8] K. A. Deere, J. M. Luckring, S. N. McMillin, J. D. Flamm, and D. Roman, "CFD predictions for transonic performance of the ERA hybrid wing-body configuration (invited)," in 54th AIAA Aerospace Sciences Meeting, p. 266, San Diego, CA, USA, 2016.

[9] H. Hoheisel, "Aerodynamic aspects of engine-aircraft integration of transport aircraft," Aerospace Science and Technology, vol. 1, no. 7, pp. 475-487, 1997.

[10] R. Rudnik, C. C. Rossow, and H. F. V. Geyr, "Numerical simulation of engine/airframe integration for high-bypass engines," Aerospace Science and Technology, vol. 6, no. 1, pp. 31-42, 2002.

[11] G. Oliveira, L. G. Trapp, and A. Puppin-Macedo, "Engine-airframe integration methodology for regional jet aircrafts with underwing engines," in 41st Aerospace Sciences Meeting and Exhibit, p. 934, Reno, NV, USA, 2003.

[12] S. Ammar, C. Legros, and J. Y. Trépanier, "Conceptual design, performance and stability analysis of a 200 passengers blended wing body aircraft," Aerospace Science and Technology, vol. 71, no. 1, pp. 325-336, 2017.

[13] P. Okonkwo and H. Smith, "Review of evolving trends in blended wing body aircraft design," Progress in Aerospace Sciences, vol. 82, pp. 1-23, 2016.

[14] D. T. Chan, J. R. Hooker, A. T. Wick et al., "Transonic semispan aerodynamic testing of the hybrid wing body with over wing nacelles in the National Transonic Facility," in 55th AIAA Aerospace Sciences Meeting, p. 98, Grapevine, TX, USA, 2017.

[15] A. Diedrich, J. Hileman, D. Tan, K. Willcox, and Z. Spakovszky, "Multidisciplinary design and optimization of the silent aircraft," in 44th AIAA Aerospace Sciences Meeting and Exhibit, pp. 1-12, Reno, NV, USA, 2006.

[16] H. Kim and M. S. Liou, "Flow simulation of N2B hybrid wing body configuration," in 50th AIAA Aerospace Sciences Meeting including the New Horizons Forum and Aerospace Exposition, p. 838, Nashville, TN, USA, 2012.

[17] C. J. Hanlon, Engine design implications for a blended wingbody aircraft with boundary later ingestion, [M.S. thesis], Department of Aeronautics and Astronautics, Massachusetts Institute of Technology, 2003.

[18] R. T. Kawai, D. M. Friedman, and L. Serrano, "Blended wing body (BWB) boundary layer ingestion (BLI) inlet configuration and system studies," Tech. Rep. NASA/CR-2006214534, NASA Langley Research Center, 2006.

[19] A. J. Anabtawi, Experimental investigation of boundary layer ingestion into diffusing inlets, [Ph.D. thesis], University of Southern California, 1999.

[20] R. H. Liebeck, "Design of the blended wing body subsonic transport," Journal of Aircraft, vol. 41, no. 1, pp. 10-25, 2004.

[21] C. A. Hall and D. Crichton, "Engine and installation configurations for a silent aircraft," American Journal of Human Genetics, vol. 58, no. 6, pp. 1239-1246, 2005. 
[22] N. Hirose, K. Asai, K. Ikawa, and R. Kawamura, "3D-Euler flow analysis of fanjet engine and turbine powered simulator with experimental comparison in transonic speed," in 20th Fluid Dynamics, Plasma Dynamics and Lasers Conference, p. 1835, Buffalo, NY, USA, 1989.

[23] N. Hirose, K. Asai, and K. Ikawa, "Transonic 3-D Euler analysis of flows around fanjet engine and T.P.S. (turbine powered simulator)," Tech. Rep. NAL-TR-1045, National Aerospace Laboratory, 1989.

[24] J. Anderson, Computational Fluid Dynamics: The Basics with Applications, McGraw-Hill Companies, Inc, New York, NY, USA, 1995.

[25] F. R. Menter, "Two-equation eddy-viscosity turbulence models for engineering applications," AIAA Journal, vol. 32, no. 8, pp. 1598-1605, 1994.

[26] W. K. Lord, G. Hendricks, M. Kirby, S. S. Ochs, R. S. Lin, and L. W. Hardin, "Impact of ultra-high bypass/hybrid wing body integration on propulsion system perrformance and operability (invited)," in 54th AIAA Aerospace Sciences Meeting, p. 267, San Diego, CA, USA, 2016. 


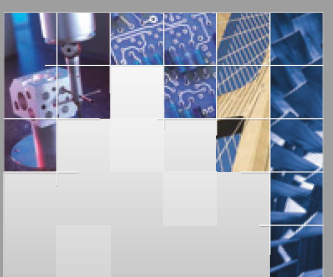

\section{Enfincering}
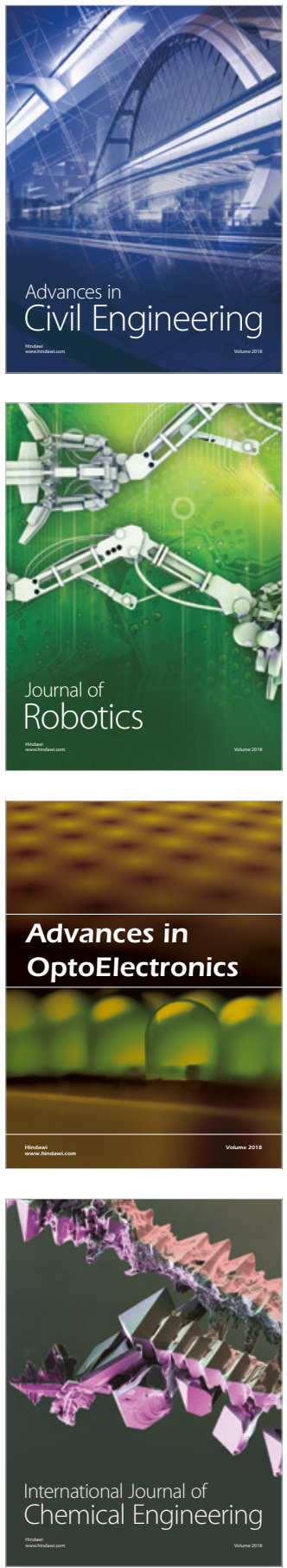

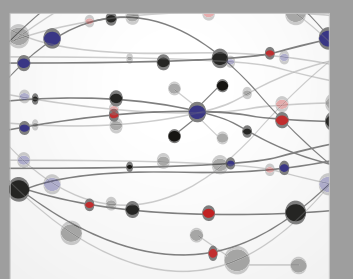

\section{Rotating \\ Machinery}

The Scientific World Journal

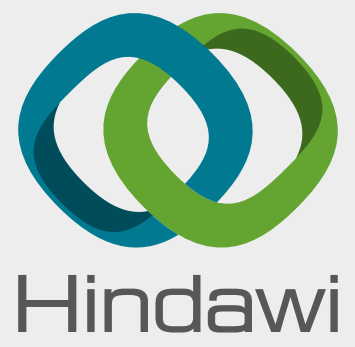

Submit your manuscripts at

www.hindawi.com
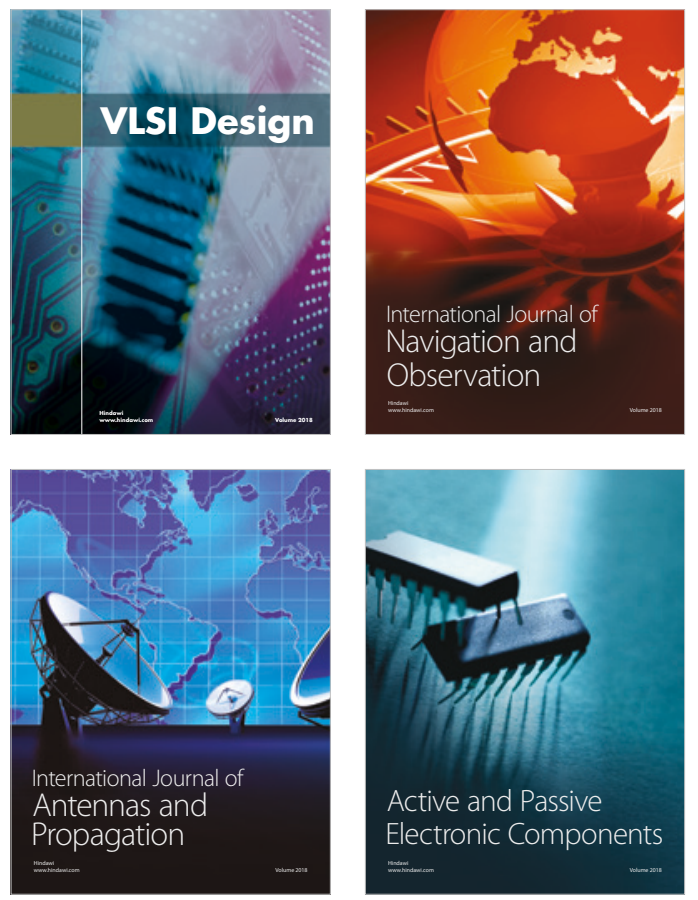
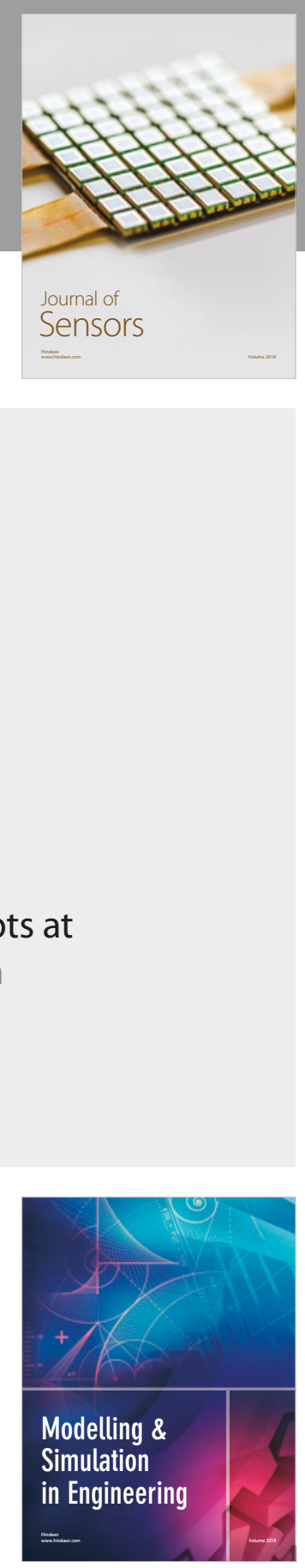

\section{Advances \\ Multimedia}
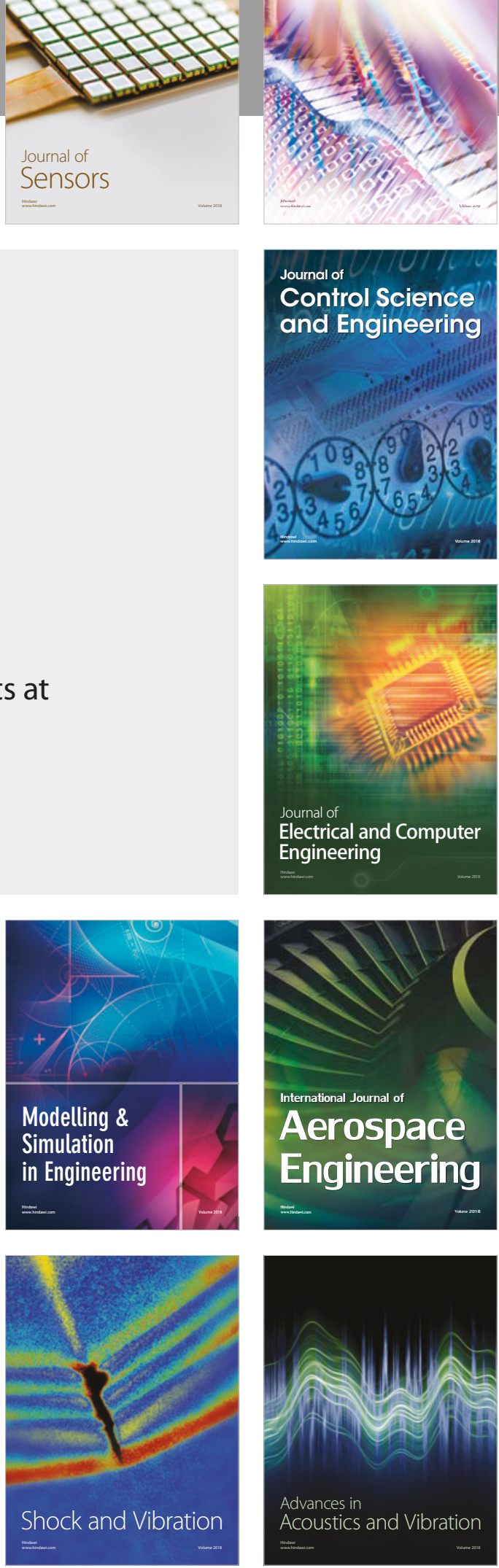